\title{
POLÍTICA E POPULAÇÃO: DADOS SOBRE UM ESTADO DE DUAS CARAS *
}

\author{
MARIA VALÉRIA JUNHO PENA **
}

\section{A QUESTÃO}

Em 1923, Monteiro Lobato escreveu uma novela intitulada $O$ presidente negro, na qual contava a história de um cientista que havia desenvolvido uma máquina do tempo. Isso the permitiu conhecer detalhadamente a vida política norte-americana nas três décadas iniciais do século XXI, culminando na eleição, em 2223 , do $87^{\circ}$ presidente dos EUA. Eram então irreconciliáveis as posições de brancos e negros diante da política eugenista do Ministério da Seleção Natural. Formaram os negros um partido político que advogava à sua raça o Sul do país, dando aos brancos o Norte. A questão em 2223, todavia, era a difusão, entre as mulheres brancas, de uma crença que as levara a formar seu próprio partido. Elas

* Agradeço a Elisa Reis, Isabel R. de Oliveira, José Tavares de Araújo Jr., Maria Lúcia Werneck, Ricardo Tolipan e Sergio Góes de Paula, o tempo que dedicaram a conversar sobre as questões aqui abordadas.

** Professora do Instituto de Economia Industrial da UFRJ.Recebido para publicação em sctembro de 1990. 
acreditavam que não eram a fêmea natural do homem, "como a leoa é do leão". Essa fêmea teria sido repudiada em épocas milenares. O homem tomara para si a fêmea de outro mamífero, vagamente assemelhado, depois de massacrá-lo. Conscientes das falhas de quaisquer arranjos matrimoniais com os homens - "o harém muçulmano, a poligamia, a monogamia, a bigamia, a poliandria, o hetairismo" - as mulheres do século XXI deviam promover o descobrimento do homem, utilizandoo provisoriamente com o único fim de manter viva a espécie.

Divididos os brancos em dois partidos, a vitória eleitoral negra foi inexorável e James Roy Wilde tornou-se o primeiro negro a ser eleito presidente dos EUA. No entanto, entre sua eleição e o dia da posse, um novo produto surgiu no mercado os raios ômega - consumidos por $97 \%$ da população de cor, que com ele alisava os cabelos, seguindo os padrões de uma nova estética. $O$ próprio presidente escolhido se omeganizara, apenas para descobrir, às vésperas de sua posse, que o produto fora a resposta branca ao novo poder negro. Além de dar novo formato aos cabelos, ele esterilizava seus consumidores masculinos, pondo fim não apenas ao poder mas, também e sobretudo, à própria população negra. O presidente eleito foi encontrado morto em seu gabinete de trabalho no dia em que deveria assumir o seu posto. Novas eleições foram convocadas e, reunidos como antigamente, homens e mulheres brancos fizeram, à sua imagem e semelhança, sem delongas e brincadeiras, o presidente seguinte. ${ }^{1}$

Por que lembrar, em 1990, esse enredo escrito em 1923 sobre 2223 ? É que parte da fabulação parece apropriada ao cenário brasileiro, senão do próximo século, ao menos do final deste. Por certo, os homens não estão sendo esterilizados; mas as mulheres, sim, em percentagens que se aproximam de $30 \%$ (entre aquelas em idade fértil) e até $40 \%$ (entre aquelas em idade fértil que vivem com algum tipo de companheiro). Provavelmente, não estão sendo esterilizadas a contragosto ou inadvertidamente. Mas o fato é que a esterilização em massa, desconhecida até a década passada, depois de vista como método aceitável de contracepção, está se tornando - e, em certas regiões do país, algumas muito pobres, já se tornou - o modo mais comum de evitar o nascimento de filhos, com conseqüências imprevisíveis sobre a distribuição espacial, social e mesmo racial da população.

Como se sabe, partidos políticos não são aqui, ao contrário dos Estados Unidos, instituições de vida longa e com clientelas muito arraigadas. Mais do que nos partidos, a dinâmica política nacional se tem concentrado no Estado, que, naquele país, aparece puramente como 'administração'. Nesse aspecto a ficção de Monteiro Lobato parece distante do nosso presente. Os partidos locais carecem de

1. MONTEIRO LOBATO. O presidente negro, Brasiliense, São Paulo, 1961. 
posição nítida e diferenciada, tanto sobre variados aspectos da vida nacional, quanto sobre direitos sociais e, especialmente, sobre direitos reprodutivos. Mas, ao Estado, tais posturas não faltam e, ao menos implicitamente, o papel do sistema de saúde pública parece central não somente nas opções - ou na falta de opções - que estão sendo oferecidas à mulheres sobre como zelar por sua saúde e controlar sua fertilidade, como na alocação de valores simbólicos sobre a maternidade.

Este trabalho lida com dados produzidos pelo Suplemento da PNAD de 1986, dedicado à investigação dos métodos contraceptivos utilizados pelas mulheres brasileiras entre quinze e 54 anos de idade, disponíveis em um Texto para discussão do IBGE. ${ }^{2}$ Os dados são poucos, pobres e não oficiais. No entanto, a demora do IBGE em publicar os resultados definitivos da investigação e sua incapacidade em prever data em que isso será feito, mais que justifica, recomenda explorar as informações de que se dispõe, antes que elas tenham apenas interesse histórico. Transformadas cautelosamente em percentuais, as freqüências das variáveis do questionário utilizado são elucidativas de alguns aspectos do manejo da fertilidade feminina dentro e pela sociedade brasileira.

Explorar um dado quer dizer atribuir-lhe um sentido. Minha intenção, portanto - reconhecendo que o que se faz por ora é apenas um exercício de busca de significados -, é tomar compreensíveis algumas dessas poucas informações preliminares, demonstrando que elas permitem uma reflexão a respeito da ação pública no delicado campo da população e da família.

Para tratar do fenômeno da contracepção, evoco, como inspiração mais geral, o estudo - já lá se vai um século - realizado por Emile Durkheim sobre o suicídio, que ainda hoje constitui uma das vigas nas quais se assenta a sociologia. Aparentemente, nada tão pessoal quanto o ato voluntário de buscar a própria morte. Tão pessoal quanto a escolha do número de filhos que se quer ter, quando tê-los e de que forma evitá-los. No entanto, depois de múltiplas tabelas montadas com as estatísticas possíveis no século XIX, somos levados a concluir, com o autor, que também na forma de morrer os indivíduos estão submetidos a uma inexorável lógica social. Uma excessiva conformidade pode produzir o suicídio ritual, da mesma forma que uma excessiva desintegração o suicídio anômico, em taxas que, ano a ano, país a país, mostram que homens, velhos, protestantes e solteiros suicidam-se mais que mulheres, católicos, jovens e casados ou viúvos, e que em períodos de guerras os números de renúncias deliberadas à vida são quase insignificantes quando comparados àquelas ocorridas em crises econômicas. $\mathrm{O}$

2. OLIVEIRA L.A. e SIMÕES C.C.S. As informaçöes sobre fecundidade, mortalidade e anticoncep̧̧̃̃o nos PN.ADs. Tcxto para discussão, no.5, IBGE, 1989. 
investigador é levado à afirmação radical de que "as causas da morte estão situadas fora de nós mais que em nós e só nos atingem se nos aventuramos a entrar em sua esfera de ação". ${ }^{3}$

Segundo os dados disponíveis, a regulação da fertilidade feminina também parece dotada de uma inegável força social. O sentido dessa força, que aqui se quer esmiuçar, constitui o objetivo deste trabalho. Em outras palavras, como Durkheim argumentou a respeito do suicídio e como Levi-Strauss o fez a respeito do casamento, nós perguntamos se a escolha de ter ou não ter filhos, e como não têlos, é assunto privado ou coletivo. A questão enfrentada pelo pesquisador é a do estabelecimento dessa razão social por trás de um fenômeno aparentemente individual.

Para essa argüição, o texto que se segue, disposto no item II, parte da recente queda de fecundidade no país, faz uma discussão sumária do quadro que os dados da PNAD fornecem sobre anticoncepção e, finalmente, enfatiza a influência, nessa questão, de organismos públicos, especialmente os de natureza governamental.

O privilégio concedido à ação do Estado deve-se a dois fatores, um de ordem pragmática, outro de ordem teórica. De um lado, não estando publicados os cruzamentos que relacionam o uso de métodos contraceptivos com renda, alfabetização ou qualquer variável de back-ground social, pelo menos por ora está afastada a possibilidade de uma análise de por que certos grupos aderem mais a essas práticas do que outros. Ou seja, há que abandonar a preocupação com as características sócio-econômicas das usuárias. Mas, se é impossível concentrar a atenção em quem consome qual método, é factivel investigar traços de sua oferta, em especial quais são ofertados, onde o são e por que tipo de agente.

Quanto aos mecanismos que interferem nessa oferta, a ação do Estado ganha relevo. Impõe-se, sobre isso, algum tipo de especulação teórica. O acompanhamento médico à saúde da mulher se revelou precário na pesquisa de 1986 (por exemplo, 38\% das mulheres entre quinze e 54 anos em Pernambuco não faziam tal acompanhamento, enquanto $30,8 \%$ das que usavam pílulas o faziam sem consulta, por sua própria conta e risco; no Rio de Janeiro, os dados eram, respectivamente, 24,8\% e 25,4\%) e o anunciado Programa de Ação Integral à Saúde da Mulher (PAISM) está com sua implementação atrasada. Apesar disso, se constata um direcionamento importante de recursos públicos para uma forma específica de se evitar a fecundidade feminina, esterilização. Das mulheres esterilizadas - e são muitas - 42,9\% realizaram a cirurgia gratuitamente e $29,2 \%$ receberam-na das mãos do Estado.

3. DURKheim E., O sutcidto. Série Os pensadores, Abril, São Paulo, 1978, p. 166. 
O século XX marcou uma inflexão importante no que diz respeito ao papel do Estado na sociedade, generalizando a crença de que o governo é público, de que a sociedade não segue par elle même, de que se todos nascem iguais ela faz com que todos não se tornem iguais; portanto, a justiça é uma questão ao menos tão importante quanto a igualdade. Em outras palavras, desde o final do século XIX o Estado passou a acreditar (e a sociedade a esperar) que fosse seu dever o exercício de políticas públicas destinadas a corrigir ou amenizar situações sociais consideradas excessivamente carentes, indignas ou danosas. Como a educação, a saúde, dentro da qual se inclui hoje o planejamento familiar, passou a ser encarada como uma questão coletiva, fosse no fornecimento de serviços destinados a mantê-la ou melhorá-la, fosse na regulação dos parâmetros da oferta desses serviços, mesmo que realizados por agências privadas. Tanto a venda de medicamentos quanto a realização ou proibição de certos atos cirúrgicos foram, aos poucos, consideradas domínios legítimos da atenção do Estado.

Ora, uma política social tem sempre a família como destino. É ela, e não indivíduos atomizados, que se quer atingir. $\mathrm{O}$ atendimento a necessidades tidas como primárias e as políticas para a família são menos significativos que a política sobre a família, sobre aquela família que se quer a imagem de todas as demais e à qual as energias individuais devem estar submetidas: decente, escolarizada, limpa, nuclear. Essa familiarização $o^{4}$ da sociedade, que o Estado contemporâneo almeja, requer medidas bem concretas: do amparo a mães solteiras, recuperação de prostitutas, hospícios e Santas Casas dos séculos passados, às creches, amparo a gestantes e crianças, merenda escolar, ensino técnico e lazer coletivo em dias de festividade pátria do século XX.

Nesse contexto, o planejamento familiar se insinua. Em sua face mais visível, ele se faz em nome da saúde pública e é em consonância com os valores desta última que seu discurso se estabelece, em princípio neutro e universal, como se as famílias decidissem e o sistema (público ou privado, mas sempre regulado e autorizado pelo Estado) fornecesse os instrumentos e prestasse os serviços requeridos. Mas, se a família não é passiva, o Estado não é neutro. O planejamento da reprodução, estranha mistura de sexo com boas maneiras, deve ser encarado como locus de encontro entre duas ordens, a do Estado e sua vontade de definição das mulheres que estão destinadas a perpetuar o cidadão e de seleção dos que devem nascer e merecer o gozo do patrimônio público; e a da família e sua economia interna de recursos, materiais e simbólicos, que tem no uso de anticoncepcionais o rosto mais evidente.

4. DONZELOT J., A policia das familias, Graal, Rio de Janeiro, 1980. 
O Estado burguês, ninguém duvida, pode ser descrito como um sistema de deveres e obrigações no qual pessoas sem eira nem beira, mendigos, pivetes, desgraçados e desempregados - que dependem de gastos públicos, de esmolas, da filantropia pública e privada - são vistos como onerosos, incontroláveis ou perigosos. Também hoje, pouco discordariam de que, na contabilidade familiar contemporânea, em uma sociedade de pensões e aposentadorias, filhos em demasia deixaram de constituir seguros contra doença, velhice e trabalho excessivo, para se tornarem uma carga, numa situação na qual tudo se troca por dinheiro. O dinheiro só se obtém com trabalho e, se o trabalho é muito, o salário é escasso. Conforme já foi observado: "Na família tradicional, a criança é, em termos econômicos, um 'bem privado', um investimento que reverterá em benefício dos pais na velhice destes. Não é mais o caso: a criança não é um bem privado a ser cuidado, mas sim um obstáculo aos papéis que os pais devem desempenhar em profissões e organizações tornadas impessoais. Elas passam a ser um 'bem público', e, como no caso dos demais bens públicos, coloca-se à questão: quem pagará seus custos? Isto é, quem tomará para si a responsabilidade de educar as crianças e investir recursos nelas? Cada vez mais, deve-se responder 'ninguém'. Os pais têm cada vez menos interesse em fazer tal investimento, e, abaixo do Estado, não existe outro ator, além da família, cujo interesse poderia justificar um investimento." 5

O aumento do número de pobres vagando pelas ruas da cidade exige esforços adicionais do Estado no momento em que se generaliza a crença no direito universal a educação, saúde, trabalho e previdência. Mas a intervenção estatal no planejamento familiar - e, mesmo, radicalmente, no controle da natalidade - não refletiria apenas a perversidade, mesmo longínqua, da inspiração malthusiana na avaliação da relação entre população e riqueza. Além de uma questão de contabilidade do Estado, uma outra, de natureza política, é proposta para o organizador da ordem pública: a ameaça de conflitos entre uma massa entendida como bárbara e uma minoria assalariada civilizada. Se tal Estado ainda é o liberal, a problemática da ordem se toma mais delicada, pois não se pode resolver apenas pela imposição ou coerção. Sua função de controle, conservação e formação de populações é desempenhada mais insidiosamente, abrindo brechas para a entrada de organizações privadas e filantrópicas (ah, a esterilização gratuita!), que prestam serviços graciosamente. Os grupos filantrópicos que distribuem alimentos, cuidam de velhos e crianças, fornecem serviços de planejamento familiar e, ainda, no Brasil dos anos 80 , controlam a natalidade, não podem ser concebidos como "uma

5. LECA J., "Individualisme et citovenneté". em BIRRAIJM P I e LECA. J., Sur l'individua lisme, Presses de la Fondation Nationale des Sciences Politiques, Paris, 1986, p. 201. 
fórmula ingênua e apolítica de intervenção privada na esfera dos problemas ditos sociais, mas sim como uma estratégia deliberadamente despolitizante, face à instrumentação dos equipamentos coletivos, ocupando um lugar nevrálgico, eqüidistante da iniciativa privada e do Estado (...) Ao invés de um direito à assistência do Estado, cujo papel seria, assim, aumentado (fornecem-se) os meios para (a população) ser autônoma, através do ensino das virtudes da poupança. Descobre-se, assim, o lema no interior do qual se pode tornar aceitável o necessário aumento dos equipamentos coletivos, sem que atentem contra a definição liberal de Estado". 6

A partir de agora, os dados passam a ser examinados dentro desse quadro, que faz da população uma questão do Estado, mas cuja ordem liberal concebe a família como instância privada e livre para regular-se.

\section{OS MÉTODOS DE CONTRACEPCÃO FEMININA NO BRASIL: O FENÔMENO DA ESTERILIZAÇÃO}

No suplemento de 1986, o IBGE retirou, da amostra da PNAD, uma subamostra de mulheres em idade fértil, que deveriam responder um questionário. Depois de perguntas usuais e de outras sobre a experiência reprodutiva de cada uma, era perguntado se estavam ou não utilizando algum método anticoncepcional. Se estavam, qual deles, como havia sido recomendado, se utilizavam método de descanso e, em caso afirmativo, qual; se não estavam, as razões, que podiam incluir gravidez, falta de companheiro, menopausa ou ter sido o companheiro esterilizado. Aparecia também a opção de que a própria mulher tivesse sido esterilizada. Nessa eventualidade, inquiria-se as razões da esterilização, se tinha sido gratuita ou paga, onde fora realizada e se havia sido feita junto com o último parto.

Este artigo usa as freqüências que apareceram nessas respostas. Como só estão disponíveis as freqüências absolutas, sujeitas a correção até que a pesquisa seja oficialmente divulgada, deve-se usar apenas percentuais. Eles se referem ao total de mulheres entrevistadas, o qual, presumivelmente, constitui uma amostra com representatividade aceitável do universo de mulheres de quinze a 54 anos de idade.

Entre 1960 e 1980 , a taxa de fecundidade total declinou, no Brasil, de 6,28 para 4,35; no Nordeste, de 7,39 para 6,13; no Sul, de 5,89 para 3,63 (ver Simões C.C.S. e Oliveira L.A.P., 1988). Mas o fato a se ressaltar é que, feitas as contas, entre 1980 e 1984 (quando, como complementoà PNAD, oIBGE realizou pesquisa

6. DONZELOT J., A policia das familias, op. cit. pp.56-7. 
sobre fecundidade, cujos resultados também não foram publicados e estão disponiveis apenas preliminarmente) a fecundidade continuou a cair, com intensidade maior do que vinha ocorrendo (tabelas I e II).

TABELA I

Taxa de fecundidade total, por situação de domicílio - 1980/84

Grandes Regiões

Taxa de fecundidade total

\begin{tabular}{lcccccl} 
& \multicolumn{3}{c}{1980} & & & 1984 \\
Brasil & total & urb. & rural & total & urb. & rural \\
Norte & 4,35 & 3,63 & 6,40 & 3,53 & 3,03 & 5,32 \\
Nordeste & 6,45 & 5,24 & 8,04 & - & 4,04 & - \\
Sudeste & 6,13 & 4,94 & 7,66 & 4,96 & 4,00 & 6,47 \\
Sul & 3,45 & 3,17 & 5,46 & 2,96 & 2,70 & 4,96 \\
Centro-oeste & 3,63 & 4,20 & 4,55 & 3,04 & 2,79 & 3,62 \\
& 4,51 & 3,97 & 5,98 & 3,38 & 3,06 & 4,57
\end{tabular}

Fonte: IBGE - Censo Demográfico e Dados Preliminares da PNAD (em Simões C.C.S. e Oliveira L.A.P., op. cit.).

TABELA II

Variação relativa da taxa de fecundidade total 1970/80-1980/84

\begin{tabular}{lll}
\hline Grandes regiões & $1970 / 80$ & $1980 / 84$ \\
Brasil & $-24,5$ & $-18,9$ \\
Norte & $-20,9$ & \\
Nordeste & $-18,5$ & $-19,9$ \\
Sudeste & $-18,6$ & $-14,2$ \\
Sul & $-33,0$ & $-16,3$ \\
Centro-Oeste & $-29,8$ & $-25,1$ \\
\hline
\end{tabular}

Fonte: IBGE - Censos Demográficos e Dados Preliminares do Suplemento à PNAD 1980 (em Idem). 
A tendência à queda da fecundidade desde 1970 já foi suficientemente examinada por demógrafos, os quais, de maneira geral, a associam ao desenvolvimento capitalista do país, à industrialização e ao avanço do assalariamento em regiões rurais, tendo sido provavelmente facilitada pela difusão de pílulas anticoncepcionais desde os anos 60 . Nesse caso, os dados não surpreendem e aparentemente apenas acompanham a teoria sobre a trajetória familiar durante a passagem de uma sociedade tradicional para a moderna, com as respectivas alterações quanto à funcionalidade do número de filhos. $\mathrm{O}$ uso de métodos anticoncepcionais, nessa situação, não pode ser entendido como causa da queda da fecundidade, mas apenas como um elemento que a facilita. As infornaç̧ões recolhidas em 1986 mostram conhecimento de métodos contraceptivos, confirmando o sucesso da pílula entre as brasileiras (tabela III). Com exceção do Maranhão, Piauí, Ceará, Paraíba, Alagoas e Sergipe, nos demais estados mais da metade das mulheres brasileiras que viviam em união estavam fazendo uso de algum método anticoncepcional; no Brasil como um todo, a percentagem alcançava $59,8 \%$, chegando mesmo a mais de $70 \%$ no Rio de Janeiro, Santa Catarina, Rio Grande do Sul, Distrito Federal e Mato Grosso do Sul. ${ }^{7}$ Pareceria, pois, razoável concluir que a associação entre transformações na sociedade brasileira e acesso a uma droga de uso fácil estaria a produzir o esperado resultado de uma disposição ao usufruto menos exagerado da instituição da maternidade, não fosse a revelação de uma nova excentricidade brasileira: o uso maciço da cirurgia da laqueadura de trompas como método de evitar filhos. Émuito provável que tal uso esteja por trás - não facilitando, como no caso da pílula, mas causando - da intensificação do ritmo de queda da fecundidade nos anos recentes (tabelas III e IV).

Chama a atenção a radicalidade da opção pela esterilização. Tudo funciona como se o indivíduo se tivesse desvalorizado a ponto de preferir eliminar de uma vez por todas suas possibilidades de reprodução que arcar com os custos de um programa de planejamento familiar. Este, provavelmente, é o sentido do dado que mostra, em 1986, a esterilização como mais popular do que a pílula no Brasil, resultado que se confirma em todos os estados, com exceção de Sergipe, Espírito Santo, Santa Catarina e Rio Grande do Sul. Nos dados da tabela III, não existe correlação significativa $(-0,19)$ que permitia concluir que a esterilização seja uma alternativa em situações nas quais a pílula não vingou. Espírito Santo, Rio de Janeiro, São Paulo e outras Unidades da Federação, mostram que a cirurgia se difunde mesmo quando a pílula é usada, confirmando a hipótese de que estamos presenciando, de fato, controle de natalidade e não planejamento familiar.

7. OLIVEIRA L.A.P. e SIMÕES C.C.S., “As informações sobre fecundidade, mortalidade e anticoncepşão nas PNADs", op. ctr. 


\section{TABELA III}

\section{Proporção de uso de métodos anticoncepcionais por} mulheres de entre 15 e 54 anos de idade -1986

\begin{tabular}{lcccccc}
\hline \multicolumn{1}{c}{ Unidade da } & \multicolumn{3}{c}{ mulheres de } & \multicolumn{4}{c}{ população } & famílias \\
& \multicolumn{3}{c}{ 15 a 54 anos*ação } & \multicolumn{4}{c}{5 anos e mais } \\
& util. & pilula & ester. & não & analf. & renda até \\
util.** & & 2SM \\
Brasil & 41,0 & 15,7 & 20,1 & 59,0 & 25,6 & 42,1 \\
Maranhão & 19,7 & 02,9 & 15,7 & 08,3 & 50,5 & 72,3 \\
Piauí. & 23,1 & 06,8 & 15,1 & 75,9 & 50,5 & 72,3 \\
Ceará & 28,9 & 11,8 & 11,8 & 71,1 & 44,5 & 66,3 \\
RGNorte & 39,3 & 12,1 & 20,2 & 60,7 & 44,8 & 66,7 \\
Paraíba & 30,2 & 10,5 & 14,5 & 69,8 & 45,6 & 71,9 \\
Pernambuco & 36,3 & 09,2 & 23,4 & 63,7 & 42,0 & 60,8 \\
Alagoas & 21,9 & 06,6 & 14,1 & 78,1 & 55,3 & 66,6 \\
Sergipe & 29,0 & 13,5 & 10,6 & 71,0 & 48,4 & 61,4 \\
Bahia & 33,1 & 11,8 & 15,6 & 66,9 & 44,1 & 58,6 \\
MGerais & 38,2 & 15,6 & 16,2 & 61,8 & 23,0 & 40,0 \\
ESanto & 44,3 & 22,8 & 19,1 & 55,7 & 23,6 & 40,0 \\
RJaneiro & 49,2 & 20,4 & 22,8 & 50,8 & 14,4 & 36,0 \\
SPaulo & 46,2 & 17,1 & 20,5 & 53,8 & 14,4 & 23,3 \\
Paraná & 45,0 & 19,7 & 21,2 & 55,0 & 21,0 & 43,2 \\
SCatarina & 50,7 & 25,9 & 15,7 & 49,3 & 14,8 & 33,0 \\
RGSul & 50,3 & 31,1 & 11,4 & 49,7 & 14,5 & 37,0 \\
MGSul & 49,9 & 16,3 & 30,6 & 50,1 & 20,4 & 37,5 \\
MGrosso & 30,7 & 12,0 & 17,0 & 69,3 & 28,2 & 29,7 \\
Goiás & 47,6 & 09,0 & 35,6 & 50,1 & 25,4 & 41,0 \\
DFederal & 48,8 & 17,1 & 22,1 & 51,2 & 15,1 & 27,2 \\
\hline
\end{tabular}

Fonte: IBGE. Dados preliminares do suplemento à PNAD-1986 (em idem) e PNAD-1986 (Corpo Básico)

* Incluindo as que não vivem em união

** Incluindo as grávidas 


\section{TABELA IV}

Percentagem de esterilizações realizadas após 1979

\begin{tabular}{lc}
\hline Unidades da Federação & Esterilizações após 1979 \\
Brasil & $\mathbf{6 2 , 7}$ \\
Maranhão & - \\
Piauí & 73,8 \\
Ceará & 63,8 \\
RGNorte & 62,8 \\
Paraíba & - \\
Pernambuco & 63,6 \\
Alagoas & 67,4 \\
Sergipe & 80,0 \\
Bahia & 72,2 \\
MGerais & 61,2 \\
ESanto & 68,6 \\
RJaneiro & 57,0 \\
SPaulo & 61,1 \\
Paraná & 62,1 \\
SCatarina & 67,4 \\
RGSul & 65,3 \\
MGrosso Sul & 55,3 \\
Goiás & 54,7 \\
DFederal & 63,9 \\
\hline
\end{tabular}

Fonte: IBGE - Dados preliminares do suplemento à PNAD-1986.

Indicadores de desenvolvimento sócio-econômico podem fornecer pistas adicionais para a compreensão do fenômeno em curso do país. Tentando-se estabelecer correlações de ordem entre, de um lado, uso de pílulas e incidência de esterilização nos vários estados (exclusive os do Norte, onde a PNAD excluiu a área rural, dificultando a comparação com outros estados), e, de outro, a taxa de analfabetismo (proporção de anallabetos na população) e uma taxa de pobreza 
(proporção de famílias cujos rendimentos totais não chegam a dois salários mínimos), os resultados apenas permitem aprofundar, sem contradizer, as afirmações anteriores. O uso de pílula está fortemente associado a tais indicadores, ou seja, é tão mais difundido quanto menor sejam o analfabetismo e a proporção de famílias pobres nas diversas Unidades da Federação. As correlações encontradas foram: (a) entre analfabetismo e uso de pílula: $-0,84$; (b) entre pobreza e uso de pílula: -0,74. Essa associação, contudo, ébastante mais fraca no caso da laqueadura, permitindo que se conclua pela existência de uma tendência à generalização do procedimento em todas as áreas do país, de forma relativamente independente de algumas poucas, mas importantes, características sócio-econômicas da população. Neste caso, as correlações de ordem foram: (c) entre analfabetismo e esterilização: $-0,51$; (d) entre pobreza e esterilização: $-0,49$. Por sua vez, o mesmo índice indica uma relativa dissociação entre a distribuição das esterilizações pelos estados em 1986 e suas respectivas taxas de fecundidade, medidas em 1980 (IBGE).

Entretanto, o exame do papel que o Estado e instituições filantrópicas vêm desempenhando nessa matéria permitem ponderar o que, de outra forma, pareceria um fenômeno errático. Para isso, a variável-chave do questionário da PNAD é o local em que as operações se realizam: hospital prado, centro de saúde pública, estabelecimento conveniado com o INAMPS ou nas próprias unidades deste último (tabela V).

Os dados revelam que, nos estados do Nordeste, o a esterilização é feita preponderantemente em locais públicos, mas em estados como Goiás e Mato Grosso do Sul, onde são muito freqüentes, as mulheres buscam hospitais ou clínicas privadas. É preciso salientar, desde já, dois aspectos da intervenção pública. Em primeiro lugar, inexiste correlação de ordem $(0,35)$ entre a incidência dessa intervenção na realização de esterilizações e a taxa de fecundidade prevalente em 1980 em cada Unidade da Federação. Nada parece indicar que o uso de recursos públicos seja direcionado de forma planejada, para que se tente combater o excesso de fecundidade através do controle de natalidade. Em segundo lugar, se se procura correlacionar a prática de esterilizações com áreas onde são altos os percentuais de famílias que auferem até dois salários mínimos por mês, encontra-se alguma relação, mas não muito significativa $(0,50)$.

Também aqui, não parece que a laqueadura corresponda a uma racionalidade estatal de inspiração malthusiana, voltada para combater a pobreza impedindo os pobres de nascer. É razoável, em vista do exposto, inferir que, embora recursos públicos consideráveis estejam sendo mobilizados com o fito de esterilizar mulheres, tal mobilização - confirmando informações já antes levantadas sobre a ausência de interrelação significativa entre incidência de laqueaduras e analfabetismo e pobreza não parcce cenlialmente planejada. U Estado parece assistir, sem 
TABELA V

Distribuição das mulheres esterilizadas, segundo local e custo da esterilização - 1986 (\%)

\begin{tabular}{lcc}
\hline Unidades da Federação & Públicos & Gratuitas \\
Brasil & $\mathbf{2 9 , 2}$ & $\mathbf{4 2 , 9}$ \\
Maranhão & 33,1 & 58,5 \\
Piauí & 76,1 & 71,6 \\
Ceará & 38,7 & 64,2 \\
RGNorte & 64,5 & 75,0 \\
Paraiba & 54,6 & 64,9 \\
Pernambuco & 45,8 & 55,2 \\
Alagoas & 44,8 & 75,9 \\
Sergipe & 05,0 & 72,5 \\
Bahia & 23,3 & 45,1 \\
MGerais & 18,5 & 41,3 \\
ESanto & 26,2 & 42,4 \\
RJaneiro & 30,0 & 37,2 \\
São Paulo & 28,5 & 34,5 \\
Paraná & 24,6 & 35,9 \\
SCatarina & 26,5 & 33,9 \\
RGSul & 20,1 & 41,4 \\
MGrosso Sul & 16,8 & 32,6 \\
MGrosso & 07,3 & 28,6 \\
Goiás & 11,3 & 26,4 \\
DFederal & 34,8 & 37,8 \\
\hline
\end{tabular}

Fonte: IBGE - Dados preliminares do suplemento à PNAD - 1986 (em idem)

interferir, uma atuação de iniciativa microssocial de seus médicos servidores, provavelmente com o acordo de direções de hospitais, enfermeiras e mulheres.

Um segundo aspecto é aquele indicado pela diferença nos percentuais entre as estcrilizaçũes gratuitas e aquelas realizadas em hospitais públicos ou con- 
veniados. Essa diferença está a indicar, precisamente, o tamanho do interesse do setor privado de caráter filantrópico nos assuntos populacionais. Ao mesmo tempo, demonstra uma espécie de radicalidade: não the assusta fazer justiça pelas próprias mãos, contribuindo, em alguns estados (Sergipe, Minas Gerais, Rio Grande do Sul), com mais recursos que o próprio Estado ou o setor privado remunerado para a realização de esterilizações.

A comparação entre as duas causas mais freqüentemente alegadas para a esterilização possibilita, ainda, um desdobramento dessa questão. Conforme mostra a tabela VI, dois são os principais motivos que, segundo as mulheres, as levam à laqueadura: problemas de saúde e número excessivo de filhos. Questões financeiras, por exemplo, não são motivos muito importantes: elas raramente aparecem em percentuais acima de dois dígitos e, quando o fazem (no Maranhão, Piauí, Ceará, Rio Grande do Norte, Pernambuco e Alagoas), jamais ultrapassam os $17,1 \%$ de Pernambuco.

Do ponto de vista médico, a esterilização só se torna indicada quando a mulher já se submeteu a um número excessivo de cesarianas. Mas a existência de problemas com a contracepção é citada por muitas mulheres como motivadora de sua laqueadura. Além de serem contra-indicadas para mulheres fumantes ou com pressão alta, pílulas podem provocar alterações no peso, náusea persistente e dores de cabeça. Em outras palavras, a freqüência com que a esterilização é justificada por razões médicas em caso de mulheres que pouco contato tiveram com médicos provavelmente esconde a falta absoluta de alternativas à gravidez. No máximo, $48,3 \%$ delas (no Rio de Janeiro) tinham o número de filhos considerado suficiente quando tomaram a decisão. $O$ fato de que, além da pílula, nenhuma outra fórmula seja possibilitada, de forma relevante, ao domínio feminino sobre sua reprodução - diafragma, espermicida, diu - permite a especulação de que, de fato, ao Estado brasileiro tornou-se mais conveniente, na década de 1980, ao invés de implementar um programa de planejamento familiar, permitir que seus agentes locais, por sua própria conta e risco, implementassem programas de esterilização. Pode ser mais barato - o ato cirúrgico tende a ocorrer durante um parto que, bem ou mal, já está sendo custeado - e mais confiável em sua radicalidade.

Assim, embora sem comandar o processo de esterilização, o Estado permite que ele ocorra como resultado de uma sistemática decisória que, provavelmente, se verifica localizada e erraticamente, embora tenha caráter expansivo. Ele assiste a implementação de uma política populacional que se faz fora dele, ou em suas franjas, por iniciativa de agentes locais, associadamente a agências privadas filantrópicas. Esses agentes contam não apenas com a passividade do Estado, mas com recursos financeiros, administrativos e de pessoal dele advindos. 


\section{TABELA VI}

Distribuição das mulheres esterilizadas relativamente ao motivo da esterilidade - 1986

\begin{tabular}{lcc}
\hline Unidades da Federação & \multicolumn{2}{c}{ Motivos da esterilização } \\
& saúde* & $\mathrm{n}^{\mathbf{o}}$ suficiente de filhos \\
Maranhão & $\mathbf{4 3 , 5}$ & $\mathbf{3 7 , 6}$ \\
Piauí & 51,5 & 31,5 \\
Ceará & 44,0 & 38,1 \\
RGNorte & 48,2 & 32,8 \\
Paraíba & 50,0 & 24,4 \\
Pernambuco & 54,0 & 18,4 \\
Alagoas & 40,0 & 34,2 \\
Sergipe & 47,2 & 36,8 \\
Bahia & 42,5 & 40,0 \\
MGerais & 34,0 & 42,7 \\
ESanto & 46,6 & 35,0 \\
RJaneiro & 45,4 & 33,7 \\
SPaulo & 32,2 & 48,3 \\
Paraná & 38,7 & 44,0 \\
SCatarina & 46,8 & 36,3 \\
RGSul & 46,3 & 36,4 \\
MGSul & 43,8 & 34,9 \\
MGrosso & 47,7 & 37,0 \\
Goiás & 51,5 & 34,4 \\
DFederal & 45,8 & 39,6 \\
\hline
\end{tabular}

Fonte: IBGE, Dados preliminares do suplemento à PNAD-1986 (em idem)

* Exclusive a alegação de número excessivo de cesáreas. 


\section{CONCLUSÃO}

Embora este não seja um texto de demógrafo, ele parte de uma curiosidade com a demografia: que razões levam as mulheres, em todo o mundo (mesmo excluindo aqueles países cujos governos obriga ao cumprimento de metas populacionai:), a se apropriar com tanta urgência das técnicas de anticoncepção que diminuem sua fertilidade? Assim, antes mesmo de iniciar-se, o texto possuía uma inspiração sociológica. A instituição da maternidade estaria em jogo. Embora culturalmente considerada prazerosa, cada vez menos mulheres querem se lambuzar com ela através de um uso excessivo. A diminuição generalizada da fertilidade estaria, a par de outros fenômenos, refletindo transformações no significado cultural dessa instituição. No entanto, tais transformações só ocorrem quando se alteram as relações entre família e sociedade, isto é, quando a monetarização da economia, o assalariamento generalizado e a expansão da ação providencial do Estado modificam o papel dos filhos, tomando-os mais um caríssimo investimento, inclusive simbólico, e menos um seguro contra a doença, a solidão e a velhice.

Nesse quadro - que inclui a disponibilidade da pílula anticoncepcional - era legítima a expectativa da queda da fecundidade ocorrida na sociedade brasileira depois dos anos $60 \mathrm{e}$, generalizadamente, nos anos 70 . O fato de ela ter continuado a cair, em ritmo mais veloz, nos primeiros anos da década de 1980, sem que nenhuma mudança tecnológica tenha ocorrido nos métodos de planejamento familiar, acendeu o interesse pelo tema. Este trabalho procurou entender essa recente queda, tendo em vista um fenômeno assinalado por dados de um suplemento PNAD de 1986: a difusão da esterilização como método contraceptivo no Brasil. Para tanto, privilegiou o papel do Estado no seu financiamento e no fornecimento das condições materiais que permitem sua ocorrência.

O planejamento familiar, tanto quanto uma questão de economia interna das famílias, é também uma questão política do Estado moderno, que não pretende e não exclusivamente por razões contábeis - ver suas cidades invadidas por ondas de pessoas sem moradia e trabalho fixos, tornando incontroláveis os ordenamentos urbanos. Através da difusão de meios para esse planejamento, um Estado de inspiração liberal intervém no domínio da família, sem ser invasivo e sem invadir o sagrado direito que ela possui de possuir-se a si própria e, assim, de se constituir privadamente. Nesses termos, o Estado brasileiro não possui explicitamente nenhum programa de controle de natalidade, que viria ferir sua lógica. $\mathrm{E}$, no entanto, não apenas as esterilizações se multiplicam, como multiplicam-se no interior do aparelho de saúde pública. Em direção à compreensão da dinâmica dessas esterilizações moveu-se esse texto. 
Resumidamente, ele constatou que, ao contrário das pílulas, a incidência das esterilizações nos diversos estados não está associada com a prevalência de analfabetismo ou de índices muito acentuados de pobreza (a pílula possui uma associação inversa). Igualmente, não se associa significativamente com suas taxas de fecundidade. Em suma, parece estar em curso um fenômeno geral de controle de natalidade, a partir de um processo de decisão que é local, gerado em unidades microssociais. Mas ele conta com a aquiescência do poder central, impedido, por sua natureza, de elaborar por si mesmo uma política intervencionista sobre a família. O fato de que a esterilização ocorre mesmo em regiões nas quais a pílula é difundida e a fecundidade é relativamente baixa confirma essa interpretação.

Por fim, este trabalho não foi capaz, a partir dos dados que possui, de compreender as raízes discursivas desse procedimento. Em outras palavras, ele não possui elementos que possibilitem compreender o diagnóstico que as agências locais e o Estado fazem, para originar suas ações e aquiescências. 


\section{RESUMO}

Política e população: dados sobre um Estado de duas caras

O trabalho lida com dados produzidos pelo Suplemento à Pesquisa Nacional por Amostra de Domicílios (PNAD) realizada em 1986 pelo IBGE, sobre o uso de métodos anticoncepcionais pelas mulheres brasileiras entre quinze e 54 anos de idade. Embora encarando o planejamento familiar como o território do encontro entre duas ordens - a primeira, aquela propriamente política e através da qual o Estado define as mulheres que estão destinadas a perpetuaro cidadão, selecionando os que devem nascer e merecer o uso do patrimônio público; e a segunda, privada, da família e de sua economia interna de recursos, inclusive simbólicos - o texto privilegia apenas uma delas. De fato, a preocupação é a de examinar características da oferta de serviços anticoncepcionais por parte de um Estado concebido com os attibutos do liberalismo e impedido, por sua natureza, de realizar uma política explícita de controle de natalidade. Nesse contexto, intriga a expansão acelerada da esterilização e sua aparente desordem: ela não se difunde associada a prevalência regional de analfabetismo ou pobreza. Ela pode se encontrar em qualquer parte, estando ausente de outras dotadas de perfil sócio-econômico semelhante. $O$ trabalho, pois, se ocupa em ordenar a desordem e em dar sentido à substituição da pilula pela laqueadura de trompa como o método mais popular de evitar uma gravidez indesejada.

\section{ABSTRACT}

\section{Policy and Population: Dat on a State with Two Different Faces}

Relying on information from a national survey (Suplemento à Pesquisa Nacional por Amostra de Domicílios) conducted by the Brazilian census office (IBGE) in 1986, the article looks at data on the birth control methods used by Brazilian women between the ages of 15 and 54 . Although family planning can be seen as a territory in which two spheres meet - the first being the political sphere itself, where the State defines the women who are destined to perpetuate the citizen and chooses those citizens who should be born and who deserve the use of the public assets, and the second being the private sphere, the sphere of the family and its internal economics, including symbolic resources - the text focuses on only one of the two. It examines the characteristics of birth control services as rendered by a State that was conceived with the attributes of liberalism and is by its very nature kept from enforcing an explicit birth control policy. Within this context, the accelerated expansion of sterilization and of its apparent disorder is intriguing: the spread of this method shows no correlation with the regional prevalence of 
illiteracy or poverty; rather, its expansion may in fact be detected in a particular geographical area while the method may be absent in another area with a similar socio-economic profile. The article is thus concerned with finding order in disorder and with understanding the replacement of the pill by tubal ligation as the most popular method for avoiding an unwanted pregnancy in Brazil.

\section{RESUME}

\section{Politique et Population: Donnees sur un Etat a Deux Visages}

Ce travail utilise des données fournies par le supplément au Recensement National par Echantillonnage de Domiciles - PNAD - réalisé en 1980 par l'IBGE et qui traitent de l'utilisation de méthodes anti-conceptionnelles par les femmes brésiliennes dont l'âge se situe entre 15 et 54 ans. Le Planning Familial est un territoire où deux logiques se rencontrent. La première, qui est politique au sens propre du terme, este celle par laquelle l'Etat définit les femmes destinées à perpétuer le citoyen par la selection de ceux qui doivent naître et mériter l'usage du patrimoine public. La seconde de ces logiques est privée, propre à la famille et à l'économie interne de ses ressources. Mais tout en reconnaissant l'existance de ces deux logiques, l'auteur n'en prend qu'une en considération. Il a en effet pour souci d'examiner les caractéristiques des services anti-conceptionnels offerts par un Etat conçu avec les attributs du libéralisme et empêché, de par sa propre nature, de mettre sur pied une politique explicite de contrôle des naissances. Dans un tel contexte, on se sent intrigué par l'expansion accélérée des stérilisations et de leur désordre apparent: leur diffusion n'est pas associée à la prévalence régionale de l'analphabétisme et de la pauvreté. On peut en effet observer leur présence indifféremment dans n'importe quel lieu même si elles sont absente dans d'autres endroits dont les caractéristiques socio-économiques sont semblables. Ce travail a donc pour but d'ordonner le désordre et de donner un sens au fait que la ligature des trompes est devenue la méthode la plus populaire d'éviter des grossesses indésirées et a supplanté en cela la pilule. 
